\title{
La usura en los intereses pactados en un título de crédito en México*
}

\section{Usure in interests agreed in a credit title in Mexico}

\author{
Carlos Ernesto Arcudia Hernández ${ }^{* *}$ \\ BLANCA TORRES ESPINOSA**
}

\section{RESUMEN}

El pagaré es un título de crédito que por sus características tiene una efectividad muy amplia. Este instrumento prevé la posibilidad de pactar intereses, o bien, ajustarse al tipo legal. Por ende, puede darse el caso de que se pacten intereses usurarios. Producto de las reformas constitucionales en materia de derechos humanos en 2011 se comenzó a aplicar el control de convencionalidad y uno de los primeros casos en ser tratados fue el de la inconvencionalidad de los intereses usurarios. La Primera Sala de la Suprema Corte de Justicia comenzó a resolver controversias sobre la interpretación del artículo 21.3 del Pacto de San José, que -en principio-consideraban inconvencional el pacto de intereses usurarios. Pero conforme se han ido produciendo los diferentes criterios

* Fecha de recepción: 10 de septiembre de 2019. Fecha de aceptación: 12 de diciembre de 2019. Para citar el artículo: Arcudia C. y Torres B. "La usura en los intereses pactados en un título de crédito en México". En Revist@ E-Mercatoria, vol. 18, n. ${ }^{\circ}$ 2, julio-diciembre 2019. DOI: https://doi.org/10.18601/16923960.v18n2.05

** Licenciado en Derecho por la Universidad del Mayab en Mérida Yucatán. Doctor en Derecho Mercantil por la Universidad Complutense de Madrid (España). Es Profesor Investigador de Tiempo Completo de la Unidad Académica Multidisciplinaria Zona Huasteca de la Universidad Autónoma de San Luis Potosí. Investigador Nacional Nivel 1 del Sistema Nacional de Investigadores del Conacyt. Correo electrónico: carlos.arcudia@ uaslp.mx

*** Licenciada en Derecho por la Facultad de Derecho de la Universidad Nacional Autónoma de México, en la ciudad de México. Doctora en Derecho Fiscal y Tributario por la Universidad de Salamanca (España). Es Profesora Investigadora de Tiempo Completo de la Unidad Académica Multidisciplinaria Zona Huasteca de la Universidad Autónoma de San Luis Potosí. Ha sido Candidata a Investigadora Nacional del Sistema Nacional de Investigadores del Conacyt. Correo electrónico: blancate@uaslp.mx 
jurisprudenciales ha ido ajustando el proceder de los juzgadores en caso de advertir usura. La evolución fue de un criterio subjetivo a uno objetivo relativo.

Palabras clave: Pagaré, usura, Pacto de San José, Costo Anual Total, intereses.

\section{ABSTRACT}

The promissory note is a credit title that by its characteristics has a very broad effectiveness. This instrument provides for the possibility of agreeing on interests, or adjusting to the legal type. Therefore, it may be the case that usury interests are settled. As a result of the constitutional reforms in the field of human rights in 2011, the control of conventionality began to be applied and one of the first cases to be treated was that of the inconvenience of usury interests. The First Chamber of the Supreme Court of Justice began to resolve controversies over the interpretation of article 21.3 of the Pact of San José, which, in principle, considered the pact of usurious interests to be inconvenient. But as different jurisprudential criteria have been produced, the proceeding of the judges has been adjusted in case of warning usury. The evolution went from a subjective criterion to a relative objective.

Key words: Promisory note, usury, Pact of San José, Total Annual Cost, interests

\section{INTRODUCCIÓN}

El derecho cambiario es una disciplina del derecho mercantil es de estricto derecho. Toda vez que se sigue varios principios establecidos en la propia legislación comercial. El artículo 78 del Código de Comercio establece que en las convenciones mercantiles cada uno se obliga en la manera y en los términos que aparezca que quiso obligarse. Si a eso sumamos que las características de los títulos de crédito de autonomía, literalidad, legitimidad e incorporación. Tenemos un instrumento jurídico muy potente.

Pues bien, el pagaré es el título de crédito más usual para documentar deudas porque está permitida la estipulación de intereses. En efecto el artículo 174 de la Ley General de Títulos y Operaciones de Crédito (LGTOC) establece que el importe del pagaré comprenderá los réditos caídos, el descuento del pagaré no vencido se calculará el tipo de interés pactado en éste ; o en su defecto al tipo de interés legal. Entonces, las partes pueden pactar libremente el interés que deseen; o bien atenerse al tipo legal que es del $6 \%$ anual. Aunado a lo anterior, los intereses pueden ser ordinarios; esto es los que se cobran por la deuda; y moratorios, los que se cobran por falta de pago. Éstos últimos son capitalizables. 
Todas estas características configuran un potencial problema con el cual la suscripción de un pagaré puede llegar a ser usuraria. La usura, según el diccionario de la Real Academia Española tiene dos acepciones aplicables a nuestro tema "Interés excesivo en un préstamo"; e, "interés ilícito que se llevaba por el dinero en el contrato de mutuo o préstamo".

Aunado a lo anterior, los títulos de crédito tienen un valor de prueba preconstituida. Y en las excepciones que señala el artículo 8 de la LGTOC no vienen contemplada la lesión, que dicho sea de paso en el ámbito mercantil es muy difícil de probar toda vez que la mercantilidad de un asunto está íntimamente relacionada con el lucro que se fundamenta en la especulación.

Ante este panorama, y derivado de la reforma constitucional en materia de derechos humanos de 2011 surge el control de convencionalidad. Y en aplicación del mismo se comenzó a invocar el artículo 21.3 de la Convención Interamericana sobre Derechos Humanos (Pacto de San José) que prohíbe la usura y cualquier otra explotación del hombre por el hombre.

Al ser norma constitucional por incorporación, según el artículo $1^{\circ}$ Constitucional ${ }_{i}$ y en control de convencionalidad, la Suprema Corte de Justicia de la Nación (SJCN) ha ido perfilando una serie de criterios jurisprudenciales que deben acatar los jueces cuando se esté ante un caso de usura por intereses derivados de un pagaré.

\section{EL PAGARÉ Y SUS CARACTERÍSTICAS}

Según Castrillón Luna, como forma impropia del contrato trayecticio, surgió el pagaré, que constituye sin duda, un instrumento eminentemente de crédito, y que con mayores ventajas que la letra de cambio (por tener una mecánica más simple) y la posibilidad de la estipulación de intereses), tomando los aspectos fundamentales de aquélla, facilita la realización de operaciones comerciales y financieras con todo el mundo, gozando de los mismos aspectos sustantivos y de la misma fuerza ejecutiva de la letra de cambio ${ }^{1}$.

El pagaré cumple funciones importantes, tanto en el campo financiero como en el comercial. Porque los pagarés son usados para la obtención de créditos en general a corto plazo, tanto por intermediarios financieros como por empresas. Igualmente pueden ser empleados para operaciones comerciales (el comprador de la mercancía a plazo firmará varios pagarés a favor

1 Victor Castrillón Luna, Tratado de Derecho Mercantil (México: Editorial Porrúa, 2011), 560. La redacción más sencilla del pagaré y de modo especial el hecho de que el firmante del pagaré se obligue como el aceptante de la letra de cambio han facilitado su empleo, lo cual puede apreciarse tanto de las estadísticas sobre los "efectos de comercio" como de los repertorios de jurisprudencia, en particular, la relativa a los procesos ejecutivos y cambiarios, Fernando SánChez Calero y Juan SánChez Calero, Instituciones de Derecho Mercantil (Madrid: Editorial Aranzadi, 2008), 90. 
del comerciante vendedor). Por otro lado, se ha difundido con amplitud el uso del pagaré como fórmula orientada al pago de las deudas de corto plazo, en especial por parte de los empresarios en relación con los proveedores ${ }^{2}$.

El pagaré es un título de crédito que contiene una promesa incondicional de pago dada por una persona llamada suscriptor a otra llamada beneficiario, de pagar una suma determinada de dinero en el lugar y fecha señalados en el documento ${ }^{3}$.

Según el artículo 170 de la LGTOC las menciones que ha de contener son las siguientes:

I. La mención de ser pagaré inserta en el texto del documento;

II. La promesa incondicional de pagar una suma determinada de dinero;

III. El nombre de la persona a quien ha de hacerse el pago (el beneficiario);

IV. La época y lugar de pago;

$\mathrm{V}$. La fecha y el lugar en que se suscriba el documento; $\mathrm{y}_{\text {, }}$

VI. La firma del suscriptor o persona que firme a su ruego o en su nombre.

Ahora bien, los pagarés -como todos los demás títulos de crédito- tienen cuatro características que los dotan de una mayor efectividad que al resto de los documentos mercantiles; éstas son la autonomía, literalidad, legitimación e incorporación

La autonomía es el estado de independencia del derecho y la obligación de un título respecto de los derechos y obligaciones de los anteriores tenedores del documento. La autonomía explica por qué el tenedor de un título de crédito no adquiere un derecho en forma derivativa, es decir, su derecho no deriva de aquel de la persona que le transmitió el título, sino que nace un derecho nuevo desde el momento en que recibe y toma el documento. La consecuencia más importante del carácter autónomo de los títulos de crédito es que durante su circulación, lo que implica también la circulación del derecho en ellos incorporado no se produce la acumulación de vicios o defectos que pudieran derivar de cada transferencia ${ }^{4}$.

Ésta característica se encuentra regulada en la fracción XI del artículo 8 de la LGTOC que dispone que solamente son oponibles las excepciones personales que tenga el demandado contra el actor en el ejercicio de la acción cambiaria derivada de un pagaré. Por otra parte, el artículo 12 de la LGTOC establece que la incapacidad de alguno de los signatarios de un título de crédito; el becho de que en éste

2 FeRnANDo SÁnCHEZ Calero y Juan SÁnCHEZ CALERO, Instituciones de Derecho Mercantil ob. cit., p. 89 .

3 Salvador García Rodríguez, Derecho Mercantil, los títulos de crédito y el procedimiento mercantil (México: Editorial Porrúa, 2009), 71.

4 Oscar Durán Díaz, Los títulos de crédito electrónicos su desmaterialización (México, Editorial Porrúa, 2009), 32-33 
aparezcan firmas falsas o de personas imaginarias, o la circunstancia de que por cualduier motivo el título no obligue a alguno de los signatarios, o a las personas que aparezcan como tales, no invalidan las obligaciones derivadas del título en contra de las demás personas que lo suscriban. Por ende, cada interviniente en un título de crédito lo hace de manera autónoma del resto.

La característica de la literalidad se traduce en el hecho que la vigencia y extensión del derecho y obligación consignada en el título de crédito se rigen únicamente por lo que resulte del texto consignado en el mismo. La literalidad es entonces la medida de un derecho o de una obligación cambiaria. Es entonces que los títulos de crédito se caracterizan por ser documentos literales en el sentido de que su contenido, extensión y modalidad depende exclusivamente de la redacción contenida en el propio título. Es decisivo, en consecuencia, el elemento objetivo de la escritura. Cualquier modificación, disminución mutación debe resultar en términos textuales en el título ${ }^{5}$.

La literalidad se encuentra regulada en los artículos $13,14,15$ y 16 de la LGTOC. El artículo 13 establece que, en caso de alteración del texto de un título de crédito, los signatarios posteriores se obligan según los términos del texto alterado, y los signatarios anteriores, según los términos del texto original. Por ende, ni siquiera una alteración al documento lo invalida. El artículo 14 de la LGTOC establece que los títulos de crédito solamente producirán sus efectos cuando contengan las menciones y llenen los requisitos señalados por la Ley y que ésta no presuma expresamente. En el caso del pagaré, hemos señalado líneas arriba las menciones que ha de contener.

El artículo 15 de la LGTOC regula un aspecto toral, sobre todo cuando se suscriben pagarés en blanco. Este precepto establece que las menciones y requisitos que el título de crédito o el acto en él consignado necesitan para su eficacia, podrán ser satisfechos por quien en su oportunidad debió llenarlos, hasta antes de la presentación del título para su aceptación o para su pago. De lo cual se deduce que si el tenedor de un pagaré suscrito en blanco llena él mismo los requisitos y menciones que faltan antes de presentarlo antes del cobro $_{i}$ no se podrá alegar que el documento fue alterado.

Por último, respecto al requisito de la literalidad, el artículo 16 de la LGTOC establece que el título de crédito cuyo importe estuviere escrito a la vez en palabras y en cifras, valdrá, en caso de diferencia, por la suma escrita en palabras.

La legitimación es la propiedad o calidad que tiene el título de crédito de atribuir a su titular, es decir, a quien lo posee legalmente, la facultad de exigir del obligado en el título el pago de la obligación que en el se consigna. La legitimación opera en favor del último tenedor del documento, esto en su 
aspecto activo, dado que en el pasivo, el deudor se legitima a su vez al pagar a quien aparece activamente legitimado ${ }^{6}$.

La característica de la legitimación se encuentra regulada en el artículo 38 de la LGTOC cuyo segundo párrafo dispone que el tenedor de un título nominativo en que hubiere endosos, se considerará propietario del título, siempre que justifique su derecho mediante una serie no interrumpida de aquéllos.

Por último, el requisito de la incorporación existe porque hay una conexión entre el título de crédito y el derecho que este representa. De tal suerte que dicho ligamen aparece en un doble sentido, viene a ser definitivo para configurar el concepto de título de crédito: primero porque la posesión del título es condición indispensable para el ejercicio y la transmisión del derecho; segundo, porque la vigencia y la extensión del derecho se rige exclusivamente en lo que resulte del título. La posesión del título es condición mínima para el ejercicio del derecho, aunque no siempre sea suficiente ${ }^{7}$.

La regulación de este precepto se desarrolla en el artículo 17 de la LGTOC que establece la obligación al tenedor de un título de exhibirlo para ejercitar el derecho que en él se consigna. Cuando sea pagado, debe restituirlo. Si es pagado sólo parcialmente o en lo accesorio, debe hacer mención del pago en el título.

Asimismo, el artículo 18 de la LGTOC establece que la transmisión del título de crédito implica el traspaso del derecho principal en él consignado y, a falta de estipulación en contrario, la transmisión del derecho a los intereses y dividendos caídos, así como de las garantías y demás derechos accesorios. Por ende, el derecho sigue la suerte del título.

La suscripción pues de un título de crédito por virtud de su autonomía, literalidad, legitimación e incorporación, lo hace sumamente potente. No requiere de mucha formalidad e incluso ni siquiera requiere ser llenado completamente. Pero no es lo único, sino que además está dotado de una fuerte exigibilidad por vía judicial como veremos en el siguiente epígrafe.

\section{CONSECUENCIAS JURÍDICAS DE LA SUSCRIPCIÓN DE UN PAGARÉ Y ACCIONES LEGALES PARA RECLAMAR SU PAGO}

Al pagaré, conforme lo dispone el artículo 174 de la Ley General de Títulos y Operaciones de Crédito (LGTOC), se aplican las disposiciones de la letra de cambio en cuando a la forma de circulación, de transmisión, de aval, acciones cambiarias y ordinarias, entre otras ${ }^{8}$.

7 Pedro Alfonso labariega VillanueVa, Concepto y caracterización de los títulosvalor, Revista de Derecho Privado Año 1: 2 (2002), p. 52.

8 Salvador García RodríGueZ, Derecho Mercantil... ob. cit., 71 
Según el párrafo segundo del mismo artículo 174 de la LGTOC y que es parte medular de nuestro análisis:

Para los efectos del artículo 152, el importe del pagaré comprenderá los réditos caídos; el descuento del pagaré no vencido se calculará al tipo de interés pactado en éste, o en su defecto al tipo legal, y los intereses moratorios se computarán al tipo estipulado para ellos; a falta de esa estipulación, al tipo de rédito fijado en el documento, y en defecto de ambos, al tipo legal.

Y el artículo 152 de la LGTOC hace referencia, ni más ni menos, a la acción cambiaria. Una de acción ejecutiva del derecho procesal mercantil. Según el artículo referido, el último tenedor de la letra (en este caso por aplicación del artículo 174 sería el pagaré) el letra puede reclamar el pago:

I. Del importe de la letra;

II. De intereses moratorios al tipo legal, desde el día del vencimiento;

III. De los gastos de protesto y de los demás gastos legítimos;

IV. Del premio de cambio entre la plaza en que debería haberse pagado la letra y la plaza en que se la haga efectiva, más los gastos de situación.

Si la letra no estuviere vencida, de su importe se deducirá el descuento, calculado al tipo de interés legal.

Esta acción cambiaria se ejerce en vía ejecutiva mercantil. Recordemos que en términos del artículo $8^{\circ}$ de la LGTOC señala que, contra las acciones derivadas de un título de crédito, sólo pueden oponerse las siguientes excepciones y defensas:

I. Las de incompetencia y de falta de personalidad en el actor;

II. Las que se funden en el hecho de no haber sido el demandado quien firmó el documento;

III. Las de falta de representación, de poder bastante o de facultades legales en quien subscribió el título a nombre del demandado, salvo lo dispuesto en al artículo 11 de la LGTOC ${ }^{9}$;

IV. La de haber sido incapaz el demandado al suscribir el título ${ }^{10}$;

9 El artículo 11 de la LGTOC dispone que quien haya dado lugar, con actos positivos o con omisiones graves, a que se crea, conforme a los usos del comercio, que un tercero está facultado para suscribir en su nombre títulos de crédito, no podrá invocar la excepción a que se refiere la fracción III del artículo 8o. contra el tenedor de buena fe. La buena fe se presume, salvo prueba en contrario, siempre que concurran las demás circunstancias que en este artículo se expresan.

10 El artículo 5 del Código de Comercio establece que toda persona que, según las leyes comunes, es hábil para contratar y obligarse, y a quien las mismas leyes no prohíben expresamente la profesión del comercio, tiene capacidad legal para ejercerlo. 
V. Las fundadas en la omisión de los requisitos y menciones que el título o el acto en él consignado deben llenar o contener y la ley no presuma expresamente, o que no se hayan satisfecho dentro del término que señala el artículo 15 de la LGTOC $^{11}$;

VI. La de alteración del texto del documento o de los demás actos que en él consten, sin perjuicio de lo dispuesto en el artículo 13 de la LGTOC $^{12}$;

VII. Las que se funden en que el título no es negociable;

VIII. Las que se basen en la quita o pago parcial que consten en el texto mismo del documento, o en el depósito del importe de la letra en el caso del artículo 132 de la LGTOC $^{13}$;

IX.- Las que se funden en la cancelación del título, o en la suspensión de su pago ordenada judicialmente, en el caso de la fracción II del artículo 45 de la LGTOC $^{14}$;

X. Las de prescripción y caducidad y las que se basen en la falta de las demás condiciones necesarias para el ejercicio de la acción; $y_{\text {, }}$

$\mathrm{XI}$. Las personales que tenga el demandado contra el actor.

Estas fracciones son un númerus clausus, no existen otras excepciones más que las plasmadas en las once fracciones del artículo 8 de la LGTOC, por ende, los títulos de crédito tienen un valor de prueba preconstituída. Es evidente, que entre las excepciones que señala el artículo 8 de la LGTOC no viene contemplada la lesión, que dicho sea de paso en el ámbito mercantil es muy difícil de probar toda vez que la mercantilidad de un asunto está íntimamente relacionada con el lucro que se fundamenta en la especulación.

Pues bien, la vía procesal que contempla el Código de Comercio para ejercer la acción cambiaria derivada de un título de crédito es el juicio ejecutivo mercantil. Para la procedencia del juicio ejecutivo mercantil, el acreedor debe contar con un título denominado "ejecutivo" y que, por ende, siguiendo la terminología de la ley, se dice "que traiga aparejada ejecución", lo cual se traduce en la posibilidad de que una vez presentada por el actor la demanda relativa, teniendo como sustento un título ejecutivo, hará permisible al juez del

11 En este caso el plazo es antes de su presentación para pago según lo dispone el artículo referido.

$12 \mathrm{Al}$ tratar sobre la literalidad hemos analizado las reglas que establece este precepto.

13 El artículo 132 de la LGTOC señala que, si no se exige el pago del pagaré a su vencimiento el suscriptor o cualquiera de los obligados en ella, después de transcurrido el plazo del protesto, tiene el derecho de depositar en el Banco de México el importe del pagaré a expensas y riesgo del tenedor, y sin obligación de dar aviso a éste.

14 La fracción II del artículo 45 de la LGTOC establece que en caso de solicitarse la cancelación de un título de crédito y el juez aprecie que la solicitud tiene fundamento ordenará, si así lo pidiere el reclamante, y fuere suficiente la garantía ofrecida por él, que se suspenda el cumplimiento de las prestaciones a que el título dé derecho, mientras pasa a ser definitiva la cancelación, o se decide sobre las oposiciones a ésta. 
conocimiento emita un auto llamado de exequendo (ejecución) con efectos de mandamiento en forma, que permitirá el secuestro de bienes para garantizar el pago de las prestaciones (principales y accesorias) reclamadas en la demanda ${ }^{15}$.

El juicio ejecutivo mercantil tiene como propósito obtener el pago inmediato y llano del crédito reclamado, o bien que se pronuncie una sentencia condenatoria de remate de los bienes que aseguren el pago del citado crédito, y no puede sujetarse dicho fallo a la condición de que la acreedora entregue las garantías del crédito para que proceda a efectuarse el remate, toda vez que esta condición además de no estar apoyada por precepto legal que así lo disponga, contraría la naturaleza del juicio ejecutivo, que impone al juzgador dictar sentencia con puntos resolutivos que condenen de inmediato al pago de las prestaciones reclamadas y de no hacerlo al remate de los bienes otorgados en garantía o secuestrados. Así las cosas, el deudor deberá efectuar el pago llano del crédito demandado u oponer excepciones y, de no hacerlo así, de ser condenado al cumplimiento de la obligación de pago y al remate de los bienes ${ }^{16}$.

Pero además de la gran eficacia jurídica del juicio ejecutivo mercantil debemos apuntar que por virtud de las reformas en materia de oralidad mercantil, a partir del 26 de enero de 2018 entraron en vigor los juicios ejecutivos orales mercantiles. Estos son procedentes - al igual que el juicio tradicional- cuando los documentos en los que traen aparejada ejecución- y cuya cuantía va de los cuatrocientos mil pesos a los 4 millones de pesos. Contra la resolución de este juicio no procede la apelación. Por lo tanto, únicamente queda el juicio de amparo, en el cual no se revisa el fondo del asunto, sino solamente que la actuación de la autoridad haya estado apegada al derecho convencional y a la CPEUM.

Hasta ahora hemos visto que las propias características del pagaré lo dotan de mucha eficacia. Que además, las excepciones que se pueden oponer son muy precisas; y la vía para ejercitar la acción de cobro es la ejecutiva mercantil que -además de ser expedita- se inicia con el requerimiento de pago

15 Victor Castrillón Luna, Tratado de Derecho Mercantil... ob. cit., 1176. En efecto, el artículo 1392 del Código de Comercio establece que presentada por el actor su demanda acompañada del título ejecutivo, se proveerá auto, con efectos de mandamiento en forma, para que el deudor sea requerido de pago, y no haciéndolo se le embarguen bienes suficientes para cubrir la deuda, los gastos y costas, poniéndolos bajo la responsabilidad del acreedor, en depósito de la persona nombrada por este. En punto al desarrollo de la diligencia de embargo el artículo 1394 del Código de Comercio establece que el procedimiento se iniciará con el requerimiento de pago al deudor, su representante o la persona con la que se entienda ${ }_{i}$ de no hacerse el pago se requerirá al demandado, su representante o la persona con quien se entiende la diligencia, para que señale bienes suficientes para garantizar las prestaciones reclamadas, apercibiéndolo que de no hacerlo, el derecho para señalar bienes pasará al actor. A continuación, se emplazará al demandado.

16 SALVAdor García RodríGUEZ, Derecho Mercantil... ob. cit., 249. 
y embargo. Esta eficacia, entendible por la celeridad que imprime el tráfico mercantil, puede dar lugar a un abuso cuando los intereses que se pactan sean notoriamente usurarios. A continuación, analizaremos el concepto de usura.

\section{CONCEPTO DE USURA}

El Diccionario de la Real Academia Española contiene dos acepciones de usura que pueden servir para nuestro estudio: la primera es "interés excesivo en un préstamo"; la segunda es aún peor: "interés ilícito que se llevaba por el dinero o el género en el contrato de mutuo préstamo".

La usura es un fenómeno que acontece muy a menudo en la simbiosis comercial de nuestro país, de ahí que haya surgido la necesidad de realizar una reinterpretación a partir del nuevo paradigma de los derechos humanos, ya que si bien el derecho a la propiedad privada es de carácter singular y disponible como lo clasifica Luigi Ferrajoli, contrario a otros derechos humanos que son de carácter universal e indisponibles, no menos cierto es que esas características no restan en lo absoluto la necesidad de la adecuada protección por parte de las autoridades mexicanas en el ámbito de su competencia.

El pacto excesivo de intereses en las convenciones mercantiles que conlleva al fenómeno de la usura transgrede el derecho humano a la propiedad privada, pues sin duda el patrimonio de aquel sobre quien se aplican tales frutos usurarios se verá disminuido y supeditado a la explotación de otra persona, incluso, podría ser que el pago de tales intereses lo coloque en estado de riesgo para cubrir sus necesidades básicas ${ }^{17}$.

Hemos expuesto líneas arriba, que la legislación mercantil prevé el pacto de intereses por las partes en un pagaré. No obstante, la propia legislación no establece una medida de lo que pudiera considerarse adecuado como interés pactado y evitar caer en la usura.

Como consecuencia de las nuevas tendencias en materia de derechos humanos, que analizaremos en el próximo apartado, es de aplicación en materia mercantil la prohibición contenida en el artículo 21.3 de la Convención Interamericana de Derechos Humanos (Pacto de San José). Esta norma establece que tanto la usura como cualquier otra forma de explotación del hombre por el hombre, deben ser prohibidas por la ley.

Existen básicamente dos criterios principales para determinar la usura y reducir los intereses usurarios, a saber: el criterio objetivo y el criterio subjetivo. El criterio objetivo parte de un límite fijo, aplicable a la generalidad de los casos; éste a su vez, puede ser absoluto, cuando en la norma se establece un margen concreto, una tasa determinada; o puede ser relativo, cuando dicho

17 Edgardo Evaristo Olvera Ruiz, La usura mercantil a partir del nuevo paradigma de los derechos humanos, Revista Multidisciplina, n. ${ }^{\circ} 22$ (2015), 8. 
límite está sujeto a un concepto dinámico en el que juegan un papel relevante las condiciones existentes en el mercado, las tasas del sistema financiero, entre otros. El criterio subjetivo, por su parte involucra conceptos sujetos a interpretación, permite al juzgador un ejercicio más libre de su arbitrio judicial, a partir de las circunstancias de cada asunto en particular, sin dejar de advertir los factores externos y las circunstancias económicas que pueden influir en la resolución del caso $^{18}$.

Los juzgadores no habían entrado en el estudio de la usura, hasta que se hizo valer - por la vía de control de convencionalidad- el artículo 21.3 del Pacto de San José. Acto seguido, analizaremos brevemente en qué consiste el control de convencionalidad, que ha sido la vía seguida para analizar ".el pacto de intereses.

\section{EL CONTROL DE CONVENCIONALIDAD}

Por virtud de la reforma constitucional publicada en el Diario Oficial de la Federación el 10 de junio de 2011 se reformó el artículo $1^{\circ}$ de la Constitución quedando con el siguiente texto:

En los Estados Unidos Mexicanos todas las personas gozarán de los derechos humanos reconocidos en esta Constitución y en los tratados internacionales de los que el Estado Mexicano sea parte, así como de las garantías para su protección, cuyo ejercicio no podrá restringirse ni suspenderse, salvo en los casos y bajo las condiciones que esta Constitución establece.

Las normas relativas a los derechos humanos se interpretarán de conformidad con esta Constitución y con los tratados internacionales de la materia favoreciendo en todo tiempo a las personas la protección más amplia.

En el nuevo segundo párrafo del texto transcrito el constituyente permanente estableció lo que se ha venido conociendo como el principio de interpretación conforme, el bloque de constitucionalidad y el control difuso. Esto es, todas las normas que se refieran a Derechos Humanos, es decir, no cualquier norma sino sólo las que se refieran a Derechos Humanos deberán interpretarse a la luz de la Constitución y de acuerdo con ella, pero no sólo eso, sino también a la luz de los tratados internacionales y aquí viene el bloque de constitucionalidad, en los que el Estado mexicano sea parte. Es decir, queda establecido que la interpretación deberá ser sólo conforme a la Constitución sino también conforme a los tratados internacionales en los que nuestro país sea parte. De tal forma que ninguna ley o ninguna interpretación de la ley podrá contravenir ni el texto constitucional, ni el tratado internacional: a ninguno de ellos ${ }^{19}$. gado, n. ${ }^{\circ} 188$ (2014), 27-28.

19 Miguel Ortíz Bahena, Ley de la Propiedad Industrial (México: Editorial Porrúa, 2015), 16. 
Para nuestro estudio resulta de trascendental importancia el concepto "control difuso de convencionalidad". Según Ferrer Mac-Gregor consiste en el examen de compatibilidad que siembre debe realizarse entre los actos y normas nacionales, y el Pacto de San José, sus protocolos adicionales y la jurisprudencia de la Corte Interamericana de Derechos Humanos (CIDH), único órgano jurisdiccional del Sistema Interamericano de Protección de los Derechos Humanos, que interpreta de manera última y definitiva el Pacto de San José. Se trata de un estándar mínimo creado por la CIDH para que en todo caso sea aplicado el corpus iuris interamericano y su jurisprudencia en los Estados nacionales que han suscrito o se han adherido al Pacto de San José y con mayor intensidad a los que han reconocido la competencia contenciosa de la $\mathrm{CIDH}_{;}$estándar que las propias constituciones o la jurisprudencia nacional pueden ampliar válidamente para también formar parte del "bloque de constitucionalidad/convencionalidad" 20 .

Las pautas para realizar el control de convencionalidad según la CIDH son las siguientes:

1) Identificar el derecho o libertad que se pretende proteger o interpretar en el catálogo contenido en los instrumentos interamericanos.

2) Identificar los casos (jurisprudencia) en los que la Corte Interamericana ya hizo una interpretación respecto al derecho o libertad que se pretende analizar, identificando la evolución o criterios que ha sostenido.

3) Comparar la semejanza fáctica entre los hechos del caso que se va a resolver y los del caso de que deriva la jurisprudencia en que se ha hecho la interpretación del derecho o libertad que nos interesa.

4) Comprobar que comparten las mismas propiedades relevantes esenciales, lo cual permite aplicar la misma consecuencia jurídica a ambos casos.

5) Verificar que la conclusión a la que se llega es compatible con el objeto y fin de la Convención Americana y que da como resultado la interpretación que más protege o menos restringe los derechos humanos ${ }^{21}$.

Pero, además queda sentado en el aludido párrafo el principio pro persona. Éste consiste en la obligación de todas las autoridades de resolver en todo tiempo favoreciendo a las personas con la protección amplia en los derechos humanos. Lo que significa una interpretación más estricta cuando se trate de restricción o limitaciones a derechos y libertades. En realidad, este principio

20 EDUARDO FERRER MAC-GREGOR, Interpretación conforme y control difuso de convencionalidad. El nuevo paradigma para el juez mexicano, Revista Estudios Constitucionales, Año: 9, n. ${ }^{\circ} 2$ (2011): 531-532.

21 Karlos Castilla, El control de convencionalidad: un nuevo debate en México a partir de la sentencia del caso Radilla Pacheco, Anuario Mexicano de Derecho Internacional, vol: XI (2011): 619. 
goza de rango constitucional por lo dispuesto en el primer párrafo del artículo $1^{\circ}$ constitucional toda vez que se encuentra previsto en el artículo 29 del pacto de San José22.

\section{RESOLUCIONES DE LA SUPREMA CORTE DE JUSTICIA DE LA NACIÓN SOBRE LOS INTERESES USURARIOS}

El máximo tribunal de justicia del país ha emitido una serie de jurisprudencias en los últimos años que han ido estableciendo pautas de actuación para actuar ante casos de usura. Son resoluciones un tanto contradictorias, pero que -poco a poco- han ido perfilando criterios de intervención judicial más precisos.

\section{A. Tesis AisladA 1A. CCLXIV/2012 (10A.) DE FEBRERO DE 2013}

Esta tesis de la Primera Sala de la SCJN establece los pasos a seguir para el análisis de la usura. Si bien no es de aplicación obligatoria para el Poder Judicial Federal, establece ciertos parámetros para analizar la usura.

En primer lugar, establece que la sanción para la usura mercantil, en cuanto lesión, es la nulidad relativa del acto jurídico. En el caso del pagaré, que es el objeto de nuestro trabajo, establece dos supuestos: si este no ha circulado; $\mathrm{o}$ si ya fue puesto en circulación.

Para el primero de los casos, que el pagaré no haya circulado, las acciones que competen al perjudicado -a su elección- son la de nulidad relativa o la reducción equitativa de las prestaciones.

En el segundo de los casos, cuando el pagaré haya sido puesto en circulación, la acción que le compete al lesionado es la de daños y perjuicios. Lo anterior porque al circular el título opera la característica de la autonomía, por lo que la nulidad de la causa que le da origen al título ya no existirá, en virtud de la persona que explotó al suscriptor no será la misma que la que intenta hacer efectivo el título, En ese caso para no perjudicar al tenedor de buena fe del título y no dejar en estado de indefensión al lesionado, se deben sustituir las acciones de nulidad y reducción por la de daños y perjuicios en contra del que causó la lesión. Tal y como ocurre en los casos de la compraventa y permuta mercantiles.

\section{B. JURISPRUDENCIA POR CONTRADICCIÓN DE TESIS \\ $1^{\mathrm{a} / J}$ 132/2012 DE FEBRERO DE 2013}

En esta contradicción de tesis la primera sala establece el criterio para evaluar los parámetros de la usura. Reitera el criterio de la tesis aislada 1a. CCLXIV/2012

22 EDUARDO FERRER MAC-GREGOR, Interpretación conforme y control difuso de constitucionalidad... ob. cit., 557. 
(10a.) de febrero de 2013 de las acciones que tiene la persona que se vea afectada por usura en la suscripción de un pagaré. Pero va más allá y concreta los elementos que ha de analizar el juzgador para determinar si se está o no en presencia de usura.

En efecto, la Primera Sala establece que Conforme a los artículos 2, 81, 385 y 388 del Código de Comercio; 17, 2230 y 2395 del Código Civil Federal ${ }_{i}$, 21, apartado 3 del Pacto de San José, se aprecia que, en el ámbito mercantil, el pacto de intereses usurarios se sanciona otorgando al afectado, a su elección la nulidad relativa o la reducción equitativa, y de manera excepcional la de daños y perjuicios.

Ahora bien, la lesión por usura debe tener lugar al momento de celebrar el pacto de intereses al tratarse de una ineficacia de tipo estructural que se da en el momento de la celebración del acto jurídico. En consecuencia, para que se actualice la figura, se deben comprobar dos requisitos:

a) Uno de tipo objetivo, consistente en la desproporción entre las prestaciones estipuladas en el pacto de intereses;

b) Otro de tipo subjetivo que se traduce en que el referido desequilibrio sea causado por la suma ignorancia, notoria inexperiencia o extrema miseria del afectado.

Ahora bien, la Primera Sala estableció que en virtud, y en atención a los principios de equilibrio procesal y litis cerrada que rigen en los juicios mercantiles, el análisis de los intereses lesivos debe hacerse a petición de parte.

\section{JURISPRUDENCIA POR CONTRADICCIÓN DE TESIS $1^{\mathrm{a} / J}$. 46/2014 (10 $)$ DE JUNIO DE 2014}

La Primera Sala abandona parcialmente los criterios sustentados en la tesis aislada y jurisprudencia anteriormente analizadas. En esta resolución la Primera Sala de la SCJN sostiene que en el sistema jurídico mexicano se prevén dos mecanismos para prohibir la usura ${ }_{i}$ como tipo penal y como ineficacia bajo la figura de la lesión. Se señala que, en materia civil y mercantil, la figura de la lesión recoge un concepto muy amplio de negocio usurario que comprende diversas formas de explotación del hombre por el hombre, así que, por regla general, se otorgan dos posibilidades: la ineficacia del contrato o la reducción equitativa de las prestaciones excesivas. La Ley mercantil le quita el carácter de ineficacia a la lesión en relación con los contratos de compraventa y permutas mercantiles, donde cabe la indemnización por daños y perjuicios ${ }^{23}$.

23 Francisco JaVIER Zamora Rocha, El control de convencionalidad en materia mercantil. El caso de los intereses usurarios, Epikeia, n. ${ }^{\circ} 37$ (2018): 16. 
La Sala argumenta que en esas resoluciones había equiparado el estudio del interés usurario con el interés lesivo, lo que provocó que se estimara que los requisitos procesales y sustantivos que rigen para hacer valer la lesión como vicio del consentimiento, se aplicaran también para que pudiera operar la norma constitucional consistente en que la ley debe prohibir la usura como forma de explotación del hombre por el hombre.

Sin embargo, la Primera Sala considera, a partir de esta resolución, que esa prohibición de la usura se encuentra inmersa en la gama de derechos humanos respecto de los cuales el artículo $1^{\circ}$ constitucional ordena que todas las autoridades, en el ámbito de sus competencias, tienen la obligación de promover, respetar, proteger y garantizar. Así resulta que el artículo 21.3 del Pacto de San José, prevé la usura como una forma de explotación del hombre por el hombre, como fenómeno contrario al derecho humano a la propiedad, lo que se considera que ocurre cuando una persona obtiene en provecho propio y de modo abusivo sobre la propiedad de otra, un interés excesivo derivado de un préstamo; pero además la ley debe prohibir la usura.

Por lo anterior la Primera Sala de la SCJN estima que el artículo 174 párrafo segundo de la LGTOC, que prevé que en el pagaré el rédito y los intereses que deban cubrirse se pactaran por las partes, y sólo ante la falta de tal pacto, operará el tipo legal, permite una interpretación conforme con la Constitución General y, por ende, ese contenido normativo debe interpretarse en el sentido de que la permisión de acordar intereses tiene como límite que una parte no obtenga en provecho propio y de modo abusivo sobre la propiedad de la otra un interés excesivo derivado de un préstamo; destacando que la adecuación constitucional del precepto legal indicado, no sólo permite que los gobernados conserven la facultad de fijar los réditos e intereses que no sean usurarios al suscribir pagarés, sino que además, confiere al juzgador la facultad para que, al ocuparse de analizar la litis sobre el reclamo de intereses pactados en un pagaré y al determinar la condena conducente (en su caso), aplique de oficio el artículo 174 indicado acorde con el contenido constitucionalmente válido de ese precepto y a la luz de las condiciones particulares y elementos de convicción con que se cuente en cada caso, a fin de que el citado artículo no pueda servir de fundamento para dictar una condena al pago de intereses mediante la cual una parte obtenga en provecho propio y de modo abusivo sobre la propiedad de su contrario un interés excesivo derivado de un préstamo.

A partir de esta jurisprudencia se puede apreciar que el derecho de acción reconocido hasta entonces en favor del afectado por la lesión para que pudiera optar por la disminución equitativa de los intereses o la nulidad relativa, sufrió un vuelco favorable para el afectado, pues se transformó de un simple derecho procesal de acción para convertirse en una protección pro persona a favor del derecho humano a la propiedad privada del afectado; por lo tanto, las autoridades se encuentran vinculadas a su protección en términos del artículo primero constitucional. Este cambio implica que la carga probatoria 
para demostrar el pacto lesivo o usurario se vea disminuida en su rigor y valoración de los elementos de prueba con los cuales se pueda acreditar, ya que constriñe al juez para que oficiosamente disminuya prudencialmente la tasa de los intereses si advierte de autos que puede llegar a existir una explotación con el pacto de intereses. Aunque vale la pena adelantar que esta actuación oficiosa y el aligeramiento de la carga probatoria en pro del afectado no son tan amplios y mucho menos ilimitados ${ }^{24}$.

\section{JURISPRUDENCIA POR CONTRADICCIÓN DE TESIS \\ 1\% J. 47/2014 (10 $\left.0^{\mathrm{a}}\right)$ DE JUNIO DE 2014}

En esta tesis jurisprudencial la Primera Sala de la Suprema Corte de Justicia de la Nación estableció que, en el caso de un pagaré, si el juzgador advierte que la tasa de interés pactada -con base en el artículo 174, párrafo segundo de la LGTOC- es notoriamente usuraria puede, de oficio, reducirla prudencialmente.

La actuación del juzgador en vigilar y analizar dicha situación, no implica de ninguna manera, que se viole la garantía de audiencia del acreedor, ya que la aplicación de la ley en sentido acorde con la CPEUM, al emitir una sentencia, no depende de la labor procesal de las partes, sino del resultado del proceso, porque el juzgador debe tomar una decisión sobre lo ya expuesto por las partes. Por lo que si el juzgador adquiere convicción de oficio de que el pacto de intereses es notoriamente usurario, acorde con las circunstancias particulares del caso y las constancias de actuaciones, entonces debe proceder, también de oficio, a inhibir esa condición usuraria apartándose del contenido del interés pactado, para fijar la condena respectiva sobre una tasa de interés reducida prudencialmente para que no resulte excesiva, mediante la apreciación razonada, fundada y motivada, y con base en las circunstancias particulares de cada caso y de las constancias de actuaciones que válidamente tenga a la vista en el momento de resolver ${ }^{25}$.

La propia sala establece como criterios que el juzgador ha de tomar en cuenta lo siguiente:

24 Edgardo EVARISTO Olvera Ruiz, La usura mercantil a partir del nuevo paradigma ...ob. cit., 20 Se aclara que no se trata del estudio de un interés lesivo por lo que no deben ser exigidos los requisitos procesales y sustantivos para hacer valer la lesión como vicio del consentimiento. Ahora, al estudiar la usura, debe hacerse como una violación al derecho humano de propiedad, como una forma de explotación del hombre por el hombre que se encuentra prohibida en el artículo 21.3 del Pacto de San José. Diana María CáZares TÉLLEZ, Derechos humanos y la interpretación judicial. Algunas observaciones, Revista del Instituto de la Judicatura Federal, n. ${ }^{\circ} 46$ (2018), 134.

25 FranCISCO JAVIER ZAMORA ROCHA, El control de convencionalidad en materia mercantil... ob. cit., 18 . 
a) El tipo de relación existente entre las partes;

b) La calidad de los sujetos que intervienen en la suscripción del pagaré y si la actividad del acreedor se encuentra regulada;

c) el destino o finalidad del crédito;

d) el monto del crédito;

e) el plazo del crédito;

f) la existencia de garantías para el pago del crédito;

g) las tasas de interés de las instituciones bancarias para operaciones similares a las que se analizan, cuya apreciación únicamente constituye un parámetro de referencia;

h) la variación del índice inflacionario nacional durante la vida del adeudo:

i) las condiciones del mercado; y,

j) otras cuestiones que generen convicción en el juzgador.

Este fue un primer gran paso en por de la solución de un problema que puede ser muy grave, por las consecuencias patrimoniales que tiene. Pero al utilizar criterios subjetivos, la cuestión se tornó aún ambigua.

\section{E. JURISPRUDENCIA 1A./J. 54/2016 (10A.) DE NOVIEMBRE DE 2016}

En esta resolución, la Primera Sala de la SCJN resolvió que la prohibición de la usura aplica tanto para intereses ordinarios como moratorios pactados en un pagaré. La Primera Sala reconoce que, en aplicación de la prohibición de la usura del Pacto de San José, debe considerarse que los intereses moratorios -si bien no son consecuencia inmediata del préstamo documentado con un pagaré- son más bien una sanción impuesta ante el incumplimiento del pago, no debe perderse de vista que el incumplimiento está directamente vinculado a la obligación de pagar o satisfacer el préstamo en la fecha pactada; por ende, la prohibición de la usura aplica tanto para los intereses ordinarios como para los moratorios.

\section{F. JURISPRUDENCIA 1ª J . 57/2016 (10ª) DE NOVIEMBRE DE 2016}

En esta resolución la SJCN estableció un criterio objetivo para determinar el interés usurario. La Primera Sala del Máximo Tribunal determinó que en la evaluación de lo notoriamente excesivo de los intereses estipulados se tendrá como referencia el valor más alto del Costo Anual Total (CAT) con respecto a operaciones similares en el mercado financiero. Cabe recordar que el Banco de México, mediante la Circular 21/2009, estableció el CAT de financiamiento expresado en términos porcentuales anuales que, para fines informativos y de comparación, incorpora la totalidad de los costos y gastos inherentes a los créditos. 
Pues bien, la Primera Sala consideró que puede utilizarse el CAT que reporte el valor más alto para operaciones similares y que corresponda a la fecha más próxima a la suscripción del título de crédito respectivo, por tratarse de un referente financiero de naturaleza activa que informa cuál es el costo de un crédito para los clientes o usuarios. La sala considera que -entre otras ventajas-, al tratarse de un indicador que incorpora varios elementos, lleva a una sobrevaluación del costo del dinero, de manera que su uso como referente es útil para advertir indiciariamente una tasa de interés usuraria, en tanto refiere al costo del dinero tolerado en el mercado del crédito.

También, permite comparar diferentes tipos de crédito, de manera que el juzgador puede tomar el CAT de un crédito hipotecario para créditos con garantías de este tipo, o el de una tarjeta de crédito para créditos quirografarios (operaciones de crédito en el que la persona física o jurídica se compromete a reembolsar el importe prestado más los intereses acordados por ambas partes mediante su firma en un pagaré), respecto de la cual el juzgador tiene un amplio margen de aplicación, pues a partir del análisis del resto de los parámetros está en aptitud de aplicar su potestad jurisdiccional y el porcentaje que corresponda según el tipo de crédito, su monto, el mercado al que se dirige y otras circunstancias útiles para su resolución. Al margen de lo anterior, si el juzgador considera que es el caso aplicar una tasa diferente del CAT, debe justificar adecuadamente su decisión.

Tenemos pues un criterio fiable y válido para que el juzgador pueda apreciar si existe o no usura. Como hemos apuntado líneas arriba, la función del CAT es informativa, pero le da al cliente que va a contratar un crédito una idea del monto que ha de pagar por él. Es un elemento que, desde nuestro punto de vista, fortalece la cultura financiera puesto que, quienes hemos tenido la necesidad de contraer una obligación con un banco, nos encontramos ante un producto complejo para el cual no nos dan muchas explicaciones. El CAT nos puede orientar, mediante un porcentaje, sobre el costo total del producto que vamos a contratar. Con esta decisión la Primera Sala trata de adoptar un criterio objetivo relativo en la determinación de la usura.

\section{G. JuRISPRUDENCIA 1ª J.28/2017 (10 $)$ DE AGOSTO DE 2017}

En este caso la Primera Sala de la SCJN estableció que el juzgador se encuentra obligado, si existen indicios, a analizar de oficio si se pactaron intereses excesivos o desproporcionados derivado de un préstamo violando el derecho humano a la propiedad garantizado en el artículo 21.3 del Pacto de San José, de ser así; deberá reducir los intereses pactados. Sin embargo, esa obligación no es irrestricta, se establece como límite el cumplimiento de los principios 
de seguridad y certeza jurídica, en este caso garantizados por el respeto a la institución de la cosa juzgada ${ }^{26}$.

Por ello, si bien al momento de emitir la sentencia correspondiente en cumplimiento a la obligación que se deriva del precepto convencional mencionado está obligado a analizar de oficio la posible configuración de la usura y, de ser el caso, actuar en consecuencia. Lo cierto es que una vez que la sentencia respectiva queda firme, esa decisión es inmutable y debe ejecutarse en sus términos; por ello, aunque el análisis de la usura puede efectuarse mientras la sentencia que condena a su pago se encuentre sub júdice, lo cierto es que una vez que la condena respectiva pierde esa característica y adquiere firmeza, necesariamente debe ejecutarse, pues ello es una consecuencia del derecho de acceso a una justicia completa y efectiva.

\section{CONCLUSIONES}

I. Los pagarés, como títulos de crédito permiten el libre pacto de intereses entre las partes. Pero cuando este acuerdo pueda producir usura, la Suprema Corte de Justicia, en aplicación del artículo 21.3 del Pacto de San José ha establecido una serie de criterios que guiarán al juzgador

II. Los criterios de la SJCN han ido evolucionando, primero estableció en una tesis aislada en la cual sostiene que si el pagaré no ha circulado; el afectado puede pedir la nulidad o la reducción de los intereses; si ya circuló, puede pedir daños y perjuicios. Complementa esta tesis una jurisprudencia en la que la SCJN determina la forma en la que ha de analizarse los intereses lesivos. Se debe comprobar un elemento de tipo objetivo: la desproporción de las prestaciones estipuladas en el pacto de intereses; y otro de tipo subjetivo: la suma ignorancia, notoria inexperiencia o extrema miseria del afectado.

III. En las siguientes resoluciones la SCJN abandona parcialmente el criterio de equiparar el interés usurario con el interés lesivo. Sostiene, entonces, que la usura afecta el derecho humano a la propiedad protegido por el artículo 21.3 del Pacto de San José. La Corte sostiene que, ante la obligación de todas las autoridades, de velar por la promoción y defensa de los derechos humanos deben actuar de oficio si en uso de la libertad contractual del artículo 174 de la LGTOC se produce usura. Se establecen como parámetros para determinar la reducción prudencial: a) El tipo de relación existente entre las partes; b) La calidad de los sujetos que intervienen en la suscripción del pagaré y si la actividad del acreedor se encuentra regulada; ${ }_{i}$ ) El destino o finalidad del crédito; d) El monto del crédito; e) El plazo del crédito; f) La existencia de garantías para el pago del crédito; g) Las tasas de interés de las instituciones

26 Diana María Cázares Tellez, Derechos Humanos y la interpretación judicial... ob cit., 136 
bancarias para operaciones similares a las que se analizan, cuya apreciación únicamente constituye un parámetro de referencia ${ }_{i}$ h) La variación del índice inflacionario nacional durante la vida real del adeudo. i) Las condiciones del mercado $;$, j) Otras cuestiones que generen convicción en el juzgador.

IV. En el siguiente paso de sus criterios interpretativos la Corte extendió a los intereses moratorios la prohibición de usura ${ }_{i}$ y estableció que puede utilizarse el Costo Anual Total como referente para evaluar lo notoriamente excesivo de los intereses estipulados. Así las cosas. La Primera Sala de la SCJN consideró que puede utilizarse el CAT que reporte el valor más alto para operaciones similares y que corresponda a la fecha más próxima a la suscripción del título de crédito respectivo, por tratarse de un referente financiero de naturaleza activa que informa cuál es el costo de un crédito para los clientes o usuarios. La sala considera que - entre otras ventajas-, al tratarse de un indicador que incorpora varios elementos, lleva a una sobrevaluación del costo del dinero, de manera que su uso como referente es útil para advertir indiciariamente una tasa de interés usuraria, en tanto refiere al costo del dinero tolerado en el mercado del crédito.

V. En el último de los casos analizados la SCJN estableció que si bien al momento de emitir la sentencia correspondiente en cumplimiento a la obligación que se deriva del artículo 21.3 del Pacto de San José está obligado a analizar de oficio la posible configuración de la usura y, de ser el caso, actuar en consecuencia. Lo cierto es que una vez que la sentencia respectiva queda firme, esa decisión es inmutable y debe ejecutarse en sus términos; por ello, aunque el análisis de la usura puede efectuarse mientras la sentencia que condena a su pago se encuentre sub júdice, lo cierto es que una vez que la condena respectiva pierde esa característica y adquiere firmeza, necesariamente debe ejecutarse, pues ello es una consecuencia del derecho de acceso a una justicia completa y efectiva.

\section{BIBLIOGRAFÍA}

Castrillón Luna, Victor. Tratado de Derecho Mercantil. México: Editorial Porrúa, 2011.

Castilla. Karlos. El control de convencionalidad: un nuevo debate en México a partir de la sentencia del caso Radilla Pacheco. Anuario Mexicano de Derecho Internacional, vol. XI, (2011), 593-624.

Cázares Téllez, Diana María. Derechos humanos y la interpretación judicial. Algunas observaciones. Revista del Instituto de la Judicatura Federal n. ${ }^{\circ} 46$ (2018): 115-142.

DURÁN DíAZ, OSCAR JORGE. Los títulos de crédito electrónicos su desmaterialización. México: Editorial Porrúa, 2009. 
Ferrer MAC-Gregor, EduARdo. Interpretación conforme y control difuso de convencionalidad. El nuevo paradigma para el juez mexicano. Revista Estudios Constitucionales Año: 9 n. 2 (2011), 531-622.

García Rodríguez, Salvador. Derecho Mercantil, los títulos de crédito y el procedimiento mercantil. México: Editorial Porrúa, 2009.

Labariega Villanueva, Pedro Alfonso. Concepto y caracterización de los títulosvalor. Revista de Derecho Privado Año:1 n. 2 (2002), 41-66.

Olvera Ruiz, EdGARdo Evaristo. La usura mercantil a partir del nuevo paradigma de los derechos humanos. Revista Multidisciplina, n. ${ }^{\circ} 22$ (2015), 6-39.

Ortíz BahenA, Miguel. Ley de la Propiedad Industrial México: Editorial Porrúa, 2015.

SÁnchez Calero, Fernando y SÁnchez Calero, Juan. Instituciones de Derecho Mercantil. Madrid: Aranzadi, 2008.

TREJO ORduña, José JuAN. El control de convencionalidad y la usura. El mundo del abogado n. ${ }^{\circ} 188$ (2014), 24-30.

ZAMORA ROCHA, FrANCISCO JAVIER. El control de convencionalidad en materia mercantil. El caso de los intereses usurarios. Epikeia n. ${ }^{\circ} 37$ (2018), 1-27. 